\title{
UNDERSTANDING BIOFILM ISSUES IN WASTEWATER PIPES: THE CASE OF NORWEGIAN AND SWEDISH MUNICIPALITIES
}

\author{
HELGE FOSSBERG, ULF RYDNINGEN \& CHRISTOPH MERSCHBROCK \\ Oslo and Akershus University College, Norway
}

\begin{abstract}
It is well known how wastewater creates biofilm in pipes. Wastewater contains many microorganisms and other materials that make the pipes particularly susceptible to biofilm formation. Biofilm is an aggregate of microorganisms, where the cells are embedded within a self-producing matrix of extracellular polymeric substance containing sugars, proteins and DNA. It can cause a reduction of the inner diameter of the pipes, which again affects the flow and self-cleaning. Turbulence can occur and cause more biofilm formation. Like other substances and objects, biofilm also contributes to reducing the pipe diameter. This is especially true in cases of water turbulence causing more biofilm. This study sets out to understand the extent to which biofilm is a problem in municipal wastewater pipes. Data was collected in Norwegian and Swedish municipalities, by using questionnaires. The results of our study confirm that biofilm formation is a problem in wastewater pipes in Norway and Sweden, especially in the long pipes. The age of the pipes, roughness, and type of material play a significant role in the formation of biofilm. Other factors can also impact the formation, such as food habits and the amount of fat in the wastewater. Another finding in our study is that biofilm formation most likely starts in the sumps of the pumphouses, but municipalities pay little attention to the maintenance of these installations. There are different cleaning techniques in use to maintain the wastewater pipelines, but the costs of maintenance are great. Biofilm formation cannot be eliminated, but the goal must be to reduce the formation, with as little resources as possible.
\end{abstract}

Keywords: biofilm, wastewater, causes of biofilm, cleaning techniques, municipalities.

\section{INTRODUCTION}

While biofilm formation in fresh-water pipes is a well-researched topic area [1], we know little research on how biofilm forms in wastewater pipes. Consequently there may be challenges within wastewater engineering that are widely overlooked by researchers and practitioners alike. Interviewing a range of senior professionals in the field led us to believe that there indeed exist a range of practical challenges in wastewater engineering that may be attributed to biofilm formation. Biofilm is an aggregate of microorganisms, were the cells are embedded within a self-producing matrix of extracellular polymeric substance containing sugars, proteins and DNA [2]-[5]. One possible explanation raised by the professionals was that pumps have gotten far more effective and cover nowadays longer stretches of pipe. As a result, wastewater increasingly settles and hardens in pipes. Consequently, biofilm begins to form and reduces the effective pipe radius triggering maintenance issues [6]. Since there is so little research in this field we decided to inquire into whether this is a more widely experienced problem in need for research. The research questions asked in this article are: Is biofilm formation in wastewater pipes a serious problem in the field and if so, what are its underlying causes? Are today's cleaning processes by self-cleaning flow, chemistry, jetting and plugs sufficient?

\section{METHOD}

To answer the research questions raised above we decided to run a questionnaire study addressed at municipal wastewater experts in both Sweden and Norway. The questionnaire 
raised 74 questions about biofilm and its implications. To identify meaningful questions for our survey we informed its design by discussions with productions operators working in a Norwegian wastewater plant. The questionnaire was facilitated based on an online system called "nettskjema" developed by researchers at the University of Oslo. The survey was sent per e-mail to most municipalities in Norway and Sweden. We addressed the survey at wastewater engineers and production operators who were asked to fill in the questions [7]. In Norway we have received answers from all 19 counties. 383 out of 426 Norwegian municipalities have received the email and answered it. Many municipalities have so-called inter-municipal collaborations and therefore one wastewater engineer may be responsible for as many as 15 municipalities which may explain the high return rate. From Sweden, we have received answers from 14 of a total of 21 counties which gives a $66.7 \%$ response rate. We have confirmed that 162 of 290 municipalities have received the email and answered it. Sweden has also inter-municipal collaborations and therefore many municipalities delivered only one answer. We have received a few emails, a total of 7 , where the questionnaires have not been answered by the original receiver. Three respondents did not want to participate. One respondent stated not having had the time to fill the 9 minutes survey. There was only one municipality responding that they had no biofilm at all. There have also been some municipalities, total of 27 who have not done the survey, but they have instead written an email to us. So that gives us a $76 \%$ response rate in total. This is a good response rate and we find this credible.

\section{RESULTS}

The results we found supported our hypothesis, confirming that biofilm is a serious problem also in waste-water pipes. The municipalities use considerable time and resources maintaining the pipelines, using different techniques.

\subsection{Biofilm formation in waste water pipes}

To understand more of the underlying causes of biofilm formation in waste water pipes, we asked the municipalities if they had experienced an increase in biofilm formation the last 20 years. Less than $60 \%$ of the municipalities had engineers that had worked for 20 years there. But of those who had, $66 \%$ thought that biofilm was an increasing problem. Furthermore we asked all the municipalities what they thought contributed to an increase in biofilm formation in waste water, and what different type of substances got caught in their biofilm aggregates. Over $90 \%$ thought food fats were a contributor, followed by food habits (see Table 1). This is reflected in the substances that are reported caught in biofilm aggregates, where fat is the most common.

Table 1: Percentage of municipalities that think the substance has contributed to increased biofilm formation.

\begin{tabular}{|l|l|}
\hline Substance & Percentage of municipalities \\
\hline Hair & 4.9 \\
\hline Food habits & 46.3 \\
\hline Starch & 4.9 \\
\hline Food fats & 92.7 \\
\hline Industry & 12.2 \\
\hline
\end{tabular}


As a comment to the food habits many municipalities said that their experience was that they had to clean the pipes more often in areas where many immigrants lived. It is tempting to believe that this increase in frequency is caused by different food habits in the immigrant population, but it can also be considered whether the immigrants might be living in places where the pipes are already old and, therefore, need more maintenance. This study does not reveal the causes of this observation.

As for substances found in biofilm aggregates, besides fat hygiene, articles like diapers and tampons were often found. Also hair, food residue and soap residue were common findings (see Fig. 1). Some municipalities reported having problems with things growing into the pipelines, such as roots from trees. These are not considered to have direct impact on the biofilm formation, but can influence the flow and indirectly cause more biofilm.

Since the biofilm is an aggregate of microorganisms it is likely that it starts to form already in the drop tank or in the sump in the pumping houses. We therefore wanted to find out how many of these installations there are. There is a great variety in how many each municipality has because of the size of each municipality (see Table 2). The smallest has only 200 inhabitants and the largest has about 920,000 inhabitants.

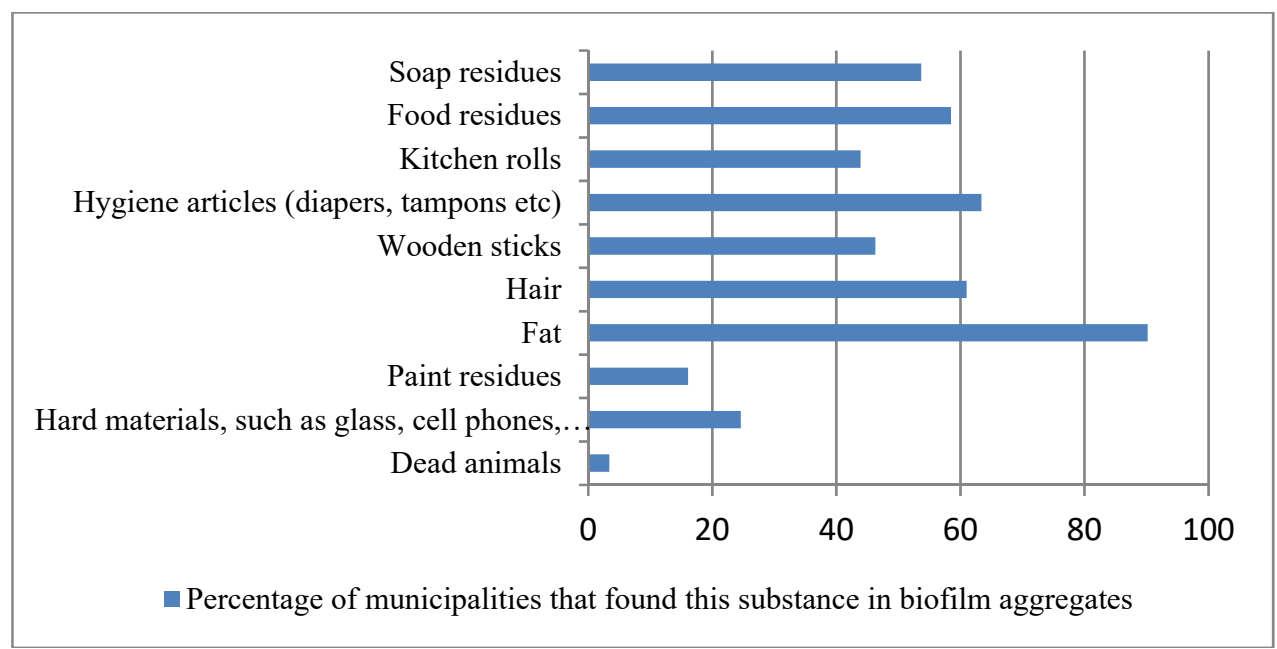

Figure 1: Substances that are most commonly found stuck in biofilm aggregates in waste water pipes, in Norwegian and Swedish municipalities.

Table 2: Number of waste water installations in municipalities in Norway and Sweden.

\begin{tabular}{|l|l|l|l|}
\hline & Average number & Minimum & Maximum \\
\hline Drop tanks & 3.6 & 0 & 10 \\
\hline Pumping houses & 46.75 & 2 & 196 \\
\hline Valves & 307 & 0 & 2500 \\
\hline Pumps & 90 & 3 & 425 \\
\hline
\end{tabular}


The wastewater has periods of standing still in all of these installations. Over long periods the biofilm is hardening, creating less volume, more resistance and decreasing the functions. The place where the wastewater is present the longest is in the sump in the pumping house. It is therefore likely that biofilm can form here. Other factors that can impact on biofilm formation are temperature of the water, surface, flow and presence of other organic material. In our questionnaire we asked the municipalities some questions to enlighten these causes (see Table 3).

Our study shows that more than $77 \%$ of the municipalities have not treated the insides of the sump. This will increase the risk of corrosion of the walls making them rougher and thereby more accessible for biofilm formation [6]. It will also demand more frequent maintenance. Almost $70 \%$ of the municipalities state that biofilm formation starts in the sump. Maintenance of these installations should therefore be given more attention.

\subsection{Pipes and maintenance}

In the questionnaire, the responders in both Norway and Sweden were asked to write down the main challenges in their work with waste water pipes. Three challenges were most frequently mentioned. The first was the age of the pipes, and by this also the maintenance of the pipes. The second was lack of expertise and recognition of the field. Interestingly, this challenge was mentioned by almost all of the responders in Norway - but none in Sweden. Whether this is an expression of difference in culture or a genuine difference in expertise in the municipalities in the two countries, is hard to tell. This could be a subject for further study. The last challenge most frequently mentioned was undersized pipes, and therefore low capacity and problems with stormwater. Other challenges that were mentioned were fat, and climate changes.

The age of the pipes affects the material and the surface within the pipe, making them more exposed to biofilm formation. Increasing roughness inside the pipelines also has an impact on the cleaning process. The average age of pipelines in Norway is 30 years [8]. In our questionnaire, $20 \%$ of the municipalities reported having pipelines older than 100 years old (see Table 4).

Table 3: The state of waste water installations in municipalities in Norway and Sweden (in percentage).

\begin{tabular}{|l|l|l|l|}
\hline & Yes & No & Don't know \\
\hline Is the pumping house well isolated & 77.8 & 18.9 & 3.3 \\
\hline Is the biofilm formation starting in the sump in pumping house & 68.9 & 17.8 & 13.3 \\
\hline Is the geometry correct in the sump & 66.7 & 32.2 & 1.1 \\
\hline Have you treated the inside of the sump with something (epoxy) & 16.7 & 77.8 & 5.5 \\
\hline Is small debris getting stuck in sliding valves & 36.7 & 32.2 & 31.1 \\
\hline Is small debris getting stuck in tilt valves & 24.4 & 26.8 & 48.8 \\
\hline Is it easy to check the valves visually & 56.7 & 31.1 & 12.2 \\
\hline Have you dimensioned the installation so that the overrun is not in use & 62.2 & 32.2 & 5.6 \\
\hline
\end{tabular}

Table 4: Age of the oldest pipeline in municipalities in Norway and Sweden.

\begin{tabular}{|l|l|}
\hline Age of the oldest pipeline & Percentage of municipalities \\
\hline Under 50 years & 31.9 \\
\hline $50-99$ years & 47.8 \\
\hline Over 100 years & 20.3 \\
\hline
\end{tabular}


Only $4.3 \%$ of the municipalities in our study had no pipelines older than 30 years. Many responders commented that the older the pipelines were, the more maintenance had to be done. Old pipes are more commonly made of concrete or cast iron. Newer pipes are made of plastic components, such as PVC or polyethylene. Municipalities have different types of pipes, due to a gradual development. If they were to buy new pipes today, over $80 \%$ of the municipalities report that they would buy pipes made of plastic material (see Table 5).

Many of the responders (34\%) commented in free-text that their experience was that pipes with much roughness in the surface had more biofilm than pipes with less roughness. The roughness of the surface is a major contributor to biofilm formation [9]. The older pipes are made of materials that are strong and stable, but with a rougher surface than the newer plastic pipes. Concrete pipes are also sensitive to low $\mathrm{pH}$, which is commonly found in wastewater, and over time this contributes to increasing roughness of the surface. Newer pipes, like PE pipes, have a smoother surface making it harder for biofilm to stick. Therefore older pipes are more exposed to biofilm formation than newer pipes.

How the pipes are put in the ground may also influence the formation of biofilm. The filling around the pipes creates a pressure against the pipe walls that can both be too high - creating an oval shaped pipe instead of circular, and too low - creating a small curve in the pipeline due to lack of support from surrounding material. In our questionnaire several municipalities said that sand, clay and swamp-materials had commonly been used in the past to fill around the pipes, but with very little success. The materials have slowly been washed out, leaving the pipe hanging with a curve. The most common filling material today is crushed stone and gravel. This is not so easily washed out. Biofilm forms more easily in still water [2], [10]. An oval shaped pipe will create a decrease in flow and shear load, and a small curve in the pipeline will create small pockets of still water were biofilm can form. To examine whether the municipalities are focused on ditch laying, we asked some questions about this in our questionnaire. The study shows that over $90 \%$ of the municipalities claim to have great focus on correct laying technique (see Table 6).

Table 5: (a) The different type of material in pipelines in municipalities in Norway and Sweden; (b) What type of pipes municipalities in Norway and Sweden would buy today - if they were making new pipelines.

\begin{tabular}{|l|l|l|}
\hline Type of material & $\begin{array}{l}\text { (a) } \\
\text { Percentage of } \\
\text { municipalities that have } \\
\text { this type of pipe }\end{array}$ & $\begin{array}{l}\text { (b) } \\
\text { Percentage of municipalities } \\
\text { that will buy this type of } \\
\text { pipe, if new lines }\end{array}$ \\
\hline Cast iron pipes & 23.1 & 4.5 \\
\hline Concrete pipes & 30.1 & 10.6 \\
\hline Ceramic pipes & 10.8 & 0 \\
\hline Polyethylene pipes & 6.4 & 31.8 \\
\hline PVC pipes & 11.8 & 24.2 \\
\hline Polypropylene pipes & 5.9 & 15.2 \\
\hline Fiberglass reinforced pipes & 6.5 & 3.1 \\
\hline Plastic pipes with constructed wall & 3.2 & 10.6 \\
\hline Other, Ethernit, asbestos & 2.2 & 0 \\
\hline
\end{tabular}


Table 6: Amount of municipalities (in percent) that follow up different parts of the ditch laying process.

\begin{tabular}{|l|l|l|l|}
\hline & Yes & No & $\begin{array}{l}\text { Don't } \\
\text { know }\end{array}$ \\
\hline Are there great focus on correct laying of the pipelines & 93.3 & 2.2 & 4.5 \\
\hline Are the requirements for execution controlled & 68.9 & 20 & 11.1 \\
\hline Are there often mistakes in the compression around the pipes & 17.8 & 66.7 & 15.5 \\
\hline Do you have an own specification for compression & 40 & 51.1 & 8.9 \\
\hline Is the compression controlled & 36.7 & 51.1 & 12.2 \\
\hline Is self-cleaning a good enough way to clean the pipes & 72.2 & 23.3 & 4.5 \\
\hline Do you know how much is leaking from pipes to ground & 21.1 & 67.8 & 11.1 \\
\hline
\end{tabular}

The type of material in the pipes and the way the pipes lay in the ground, influence the choice and result of the cleaning methods. It is important to have the right vertical drop for self-cleaning and preferably an evenly distributed drop. The length of the pipe is also important for the cleaning methods, and also impact on biofilm formation. The longest pipes are harder to clean, and more easily exposed to issues that can reduce flow and stimulate biofilm formation. 54\% of the municipalities in Norway and Sweden reported that their longest pipeline was between 1000 and 5000 meters. $18 \%$ had longer pipelines, while $27 \%$ had their longest pipeline shorter than 1000 meters (see Table 7).

To maintain the pipelines, there are different types of cleaning techniques that can be used. By far the most common techniques in the municipalities in Norway and Sweden are self cleaning and jetting. $72 \%$ and $62 \%$ of the municipalities report that they use these. Plugging is used by $46 \%$ of the municipalities, and a small amount report to use continuous flow and/or chemistry (see Table 8).

Most of the municipalities reported to use more than one technique. Our study shows that the Swedish municipalities use more jetting than in Norway. The share of municipalities in Sweden that report to use jetting is $7 \%$ higher than in Norway, and they report less use of self-cleaning than the Norwegian municipalities. In long pipelines, many municipalities use plugs as a cleaning method (see Fig. 2). We therefore asked some questions about the use of plugs in maintenance.

Table 7: The length of the longest pipeline in the municipalities in Norway and Sweden.

\begin{tabular}{|l|l|}
\hline The length of the longest pipeline & Percentage of municipalities \\
\hline Under $1000 \mathrm{~m}$ & 27.7 \\
\hline $1000-5000 \mathrm{~m}$ & 54.2 \\
\hline Over $5000 \mathrm{~m}$ & 18.1 \\
\hline
\end{tabular}

Table 8: The type of cleaning methods used in the municipalities in Norway and Sweden. Each municipality could select more than one technique.

\begin{tabular}{|l|l|}
\hline Type of cleaning technique & Percentage \\
\hline Continuous flow & 17.2 \\
\hline Self cleaning speed & 72.4 \\
\hline Chemistry & 9.2 \\
\hline Jetting & 62.1 \\
\hline Plugs & 46.0 \\
\hline
\end{tabular}


Does the plugs often get destroyed?

Does the pipeline material influence the frequency of plug driving?

Does the pipeline lenght influence the frequency of plug driving?

Are plugs a good way to remove biofilm

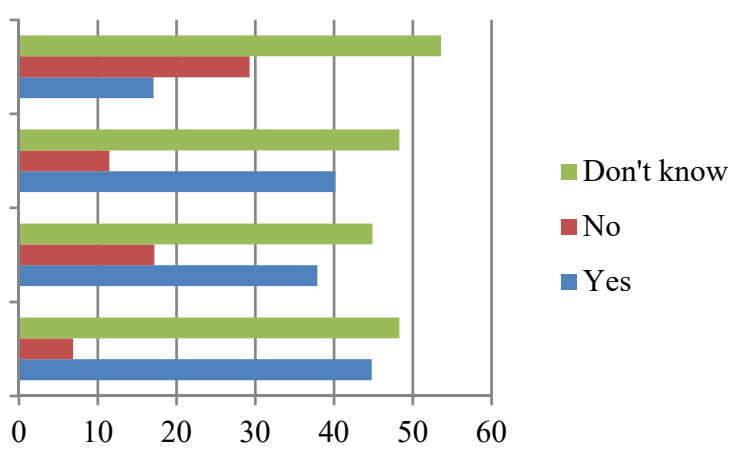

Figure 2: Elaborating on use of plugs in municipalities in Norway and Sweden; percent of municipalities that agree or disagree on the following statements.

Many municipalities reported that they should to do more plug driving, but because it takes about 3-8 hours each time they do not have the manpower or resources to do it as often as it should be done. The cost in plugs each month varies from 0 to about 30,000 Norwegian kroner (NOK) in the municipalities. Those who use 0 NOK are the same that report that they do not use plugs. The municipalities that use plugs, use an average of 6.8 hours a month at plug driving. There is also a variety in the quality of the plugs, from soft to hard. To remove biofilm it is better with hard plugs, but the hard plugs have trouble maneuvering inside the pipelines. Many municipalities that have plugs, report that they do not have a plan for how to use them. This might contribute to increase the times spend in plug driving, and also the quality of the procedure. Fig. 3 below shows where the municipalities report the most difficulties in using plugs (see Fig. 3).

In short plugging demands great use of resources, both in manpower, time and money. It is seldom used in short pipelines, and is therefore not sufficient alone. Most municipalities therefore use different types of techniques in maintaining their pipelines. All in all more than $60 \%$ of the municipalities report to use between 1 and 29 hours per month maintaining the pipelines using different techniques. Almost 19\% have less than 1 hour per month of maintenance, and a little over 5\% use more than 100 hours a month maintaining the pipelines (see Table 9).

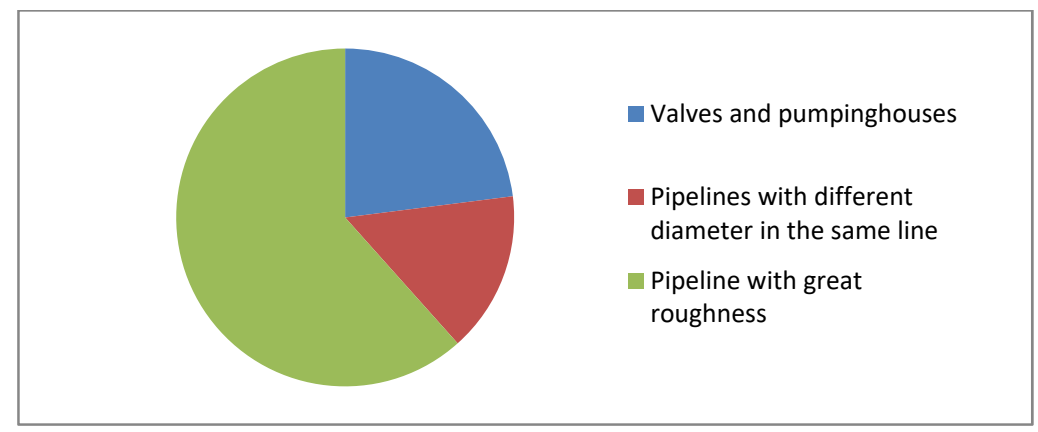

Figure 3: Where the municipalities (in percent) find it most difficult to use plugs in wastewater pipelines. 
Table 9: Amount of hours per month spend maintaining pipelines in the different municipalities.

\begin{tabular}{|l|l|}
\hline How many hours per month & Percentage of municipalities \\
\hline 0 & 18.8 \\
\hline $1-5$ & 43.4 \\
\hline $6-29$ & 24.6 \\
\hline $30-99$ & 7.6 \\
\hline $100-$ up to 1700 & 5.6 \\
\hline
\end{tabular}

Some municipalities report that they use pressure measurements to know when to clean a pipe. When the biofilm grows, the pressure inside the pipelines differs and this can be detected by an alarm that is set off by changes in pressure.

The frequency of pipe-cleaning also varies between the different municipalities, from "never" to "every day". There were no clear differences between the countries (see Fig. 4).

The municipalities reported to use different techniques and different frequency of cleaning. To understand some of the underlying causes for this, we asked if pipe length and pipe material had an impact. Over $50 \%$ of the municipalities reported that the different pipe materials influenced the technique and frequency of cleaning. About $60 \%$ reported that pipe length influenced the technique and frequency of cleaning. Studies have shown that biofilm formation is more common in longer pipes and pipes with rougher surfaces (see Table 10). Our study confirms that these type of pipes also require more maintenance.

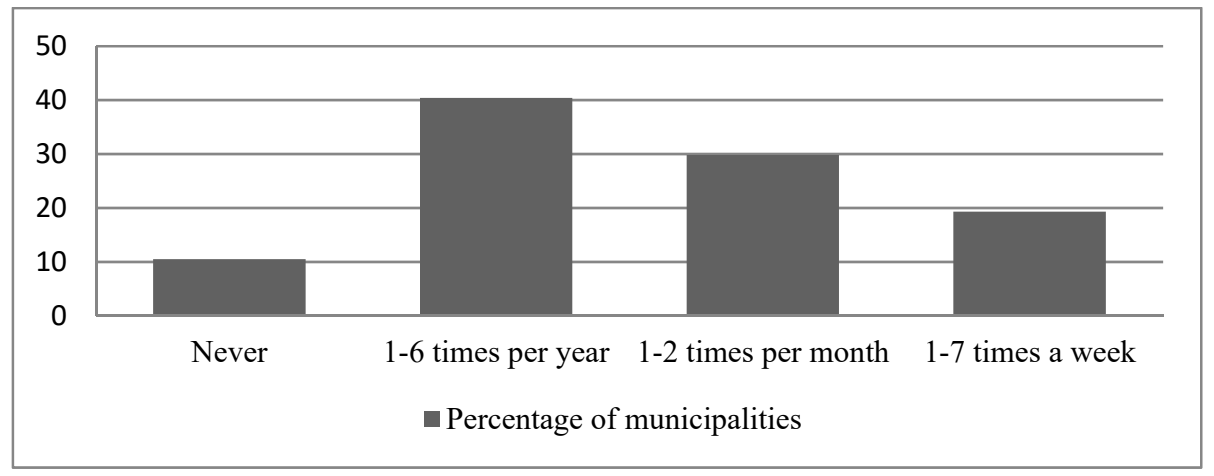

Figure 4: Frequency of cleaning waste water pipes in municipalities in Norway and Sweden.

Table 10: Percentage of municipalities that report that pipe material and/or pipe length affect cleaning techniques and frequency.

\begin{tabular}{|l|l|l|l|}
\hline Does the type of pipe material affect: & Yes & No & Don't know \\
\hline Cleaning technique & 58.5 & 31.7 & 9.8 \\
\hline Cleaning frequency & 53.7 & 36.6 & 9.7 \\
\hline Does pipe length affect: & Yes & No & Don't know \\
\hline Cleaning technique & 60.5 & 26.8 & 12.7 \\
\hline Cleaning frequency & 59.5 & 29.3 & 11.2 \\
\hline
\end{tabular}


The municipalities report in the questionnaire that concrete pipelines demands the most maintenance. The easiest material to clean with jetting is reported to be PVC pipes, and the most difficult is concrete pipes. But it is not just the length and the material that affect the choice of cleaning technique and frequency. In our study, municipalities report that the type of pipe, whether it is a pressure pipeline or a gravity drainage pipeline, also influences the choice of cleaning technique. The short pressure pipelines can manage without maintenance if they have the right design and vertical drop. The long pipelines have to be cleaned by using maximal pumping, plugging or self cleaning. Jetting is often thought to be the best cleaning technique, but is not sufficient if the pipes are more than 200 meters long.

\section{DISCUSSION}

The goal of this research was to uncover whether biofilm formation is a problem in waste water pipes or not, what the underlying causes are and if todays cleaning methods are sufficient. The study showed that over $60 \%$ of the municipalities responding experienced biofilm formation as an increasing problem. In our questionnaire we asked if the biofilm had increased the past 20 years, and many municipalities therefore did not answer. They had no engineers with that long experience in the work field. The response rate was only $39 \%$. The result is therefore associated with some uncertainty. But if we look at other questions in our questionnaire, the municipalities confirm to have biofilm in their waste water pipes, they confirm to spend considerable hours maintaining the pipelines, and as many as $68 \%$ state that they think biofilm formation starts in the sump in the pumphouse. The study therefore confirms that biofilm formation is a problem in waste water pipes, and most likely it is an increasing problem.

As for the causes of biofilm in waste water, other studies have shown that fat often contribute to biofilm formation [6]. This is confirmed in our study. More than $90 \%$ of the municipalities state that the main organic substance in wastewater contributing to biofilm is fat. Fat is also the substance most often found in biofilm aggregates in the municipalities.

To keep up the flow in the pipes, the municipalities have to maintain them. There is a great variety in how many hours and resources the different municipalities use maintaining the pipelines. Only $18 \%$ claim to use less than 1 hour a month, while most of the municipalities use between 1 and 29 hours a month. Our study shows that more than $50 \%$ of the pipes in the municipalities today are made of old material like cast iron, concrete or ceramic. These materials have a rougher surface than the newer plastic pipes, and are therefore more exposed to biofilm formation. The municipalities confirm that there is more maintenance with the old pipes than with the newer plastic pipes.

To maintain the pipes the municipalities report to use different cleaning techniques. There are three main cleaning techniques which are self-cleaning speed, jetting and plugs. Jetting is due to practical reasons preferable for pipelines up to $200 \mathrm{~m}$. Over this distance it is either self-cleaning speed or plugs which is used in the maintenance.

Self-cleaning is the cheapest method of cleaning, with practically no cost. But the effect of this method relies on many factors that are difficult to change if they were not done right when the pipeline was created. The topography is not always giving the correct vertical drop, and because of incorrect or washed-out filling around the pipes they will at other times get small verticals elevations/curves. If the total vertical drop of the wastewater is reduced, it is important to have enough flow to ensure the self-cleaning speed for maximizing the shear load in the pipe. Municipalities in our study state that they pay great attention to ditch laying, to ensure the right elevation and compression of the pipeline. At the same time, almost all the municipalities in Norway state that one of the main challenges in the field of waste water is that there are not enough expertise in the municipality. Knowing that planning the waste 
water pipeline and maintenance is of great importance, it is a major concern that the engineer expertise might be missing in the municipalities in Norway. It is also interesting that none of the municipalities in Sweden seem to have this concern. This should be a topic of further investigation in other studies.

With the right expertise in the municipalities one could also look at whether the money used to maintain the pipelines rather should be used in investing in new pipelines. The cleaning techniques that exist seem to be sufficient to remove biofilm, but require considerable resources. Almost $70 \%$ of the municipalities think that biofilm formation starts in the sump of the pumphouse, but yet only $17 \%$ have treated the surface of the sump to prevent corrosion and biofilm formation. Based on our study, preventing biofilm formation in waste water installations like the pumphouses, should be a topic of further discussion and elaboration.

\section{REFERENCES}

[1] Norsk Vann Rapport 206, 2014, Biostabilitet i drikkevannsnett.

[2] Store Norske Leksikon, Norway. Online, https://sml.snl.no/biofilm

[3] Watnick, P. \& Kolter, R., Biofilm, city of microbes. J Bacteriol, 182, pp. 2675-2679, 2000.

[4] Stoodley, P., Sauer, K., Davies, D.G. \& Costerton, J.W., Biofilms as complex differentiated communities. Annu Rev Microbiol, 56, pp. 187-209, 2002.

[5] O’Toole, G., Kaplan, H.B. \& Kolter, R., Biofilm formation as microbial development. Annu Rev Microbiol, 54, pp. 49-79, 2000.

[6] Norsk Vann Rapport 185, 2011. Fett i avløpsnett.

[7] Survey online, https://nettskjema.uio.no/answer/78978.html

[8] Statistisk sentralbyrå, Norway. Online, https://www.ssb.no/statistikkbanken/ selectvarval/saveselections.asp

[9] Ammar, Y., Swailes, D., Bridgens, B. \& Chen, J., Influence of surface roughness on the initial formation of biofilm. Surface and Coatings Technology, 284, pp. 410-416, 2015.

[10] Ducoste, J.J., Keener, K.M. \& Groninger, J.W., Fats, Roots, Oils and Grease (FROG) in Centralized and Decentralized Systems. WERF Report 03-CTS-16T, IWA Publishing: London, UK, 2009. 